\title{
Neuroendocrine Dysfunction in Genetic Subtypes of Primary Unipolar Depression
}

\author{
Bernard J. Carroll, John F. Greden, Michael Feinberg, Norman Mcl. James, \\ Roger F. Haskett, Meir Steiner, and Janet Tarika
}

Received Februarv 2, 1980; revised version received April 16, 1980; accepted April 18, 1980.

\begin{abstract}
Disinhibited activity of the hypothalamic-pituitary-adrenocortical (HPA) neuroendocrine system, characterized most specifically by abnormal responses to the dexamethasone suppression test (DST), is observed in $40-50 \%$ of patients with endogenous depression. The heterogeneity of endogenous depressives with respect to this neuroendocrine marker is so far unexplained. A recent report from lowa suggested that genetic factors could account for this heterogeneity, since abnormal DST responses were found with widely differing frequencies among primary unipolar depressives subtyped by the genetic criteria of Winokur. We studied 14 patients with primary endogenous delusional unipolar depression. Abnormal DST responses were found in $79 \%$ of the entire group, and with similar frequencies among each of the Winokur subtypes. In particular, five of six patients $(83 \%)$ with depression spectrum disease had abnormal DST results. This contrasts with a frequency of $4 \%$ reported by the lowa group. We conclude that disinhibited HPA activity does occur in depression spectrum disease when a delusional endogenous depression is present. Our results and those of the lowa study could both be consistent with a threshold model of HPA activation. The high frequency of positive DST results in delusional endogenous depressives may be determined by disinhibited central pain mechanisms. Variations in this clinical dimension, combined with variations in threshold for HPA activation by pain mechanisms, could account for the heterogeneity of DST responses among endogenous depressives.
\end{abstract}

Key Words. Depression, endogenous, delusional, genetics, neuroendocrine.

The neuroendocrine research strategy has revealed several types of functional disturbance in depressed patients, of which the best documented is disinhibition of the hypothalamic-pituitary-adrenocortical (HPA) system (Carroll, 1978). A consistent finding is that $40-50 \%$ of patients with endogenous depression have abnormal responses to the overnight dexamethasone suppression test (DST) (Carroll and Mendels, 1976; Carroll, 1977; Carroll et al., 1976b, in press; Brown et al., 1979; Schlesser et al., 1979). An important issue in this area is the heterogeneity of patients with endogenous depression with respect to this neuroendocrine marker. Attempts to distinguish convincingly between those with normal and abnormal DST responses by clinical features have been unsuccessful (Carroll and Davies, 1970; Carroll, 1972; Carroll et al., 1976b; Brown et al., 1979; Schlesser et al., 1979). So far, only the clinical

Bernard J. Carroll, M.D., Ph.D., is Director; Iohn F. Greden, M.D., is Associate Professor; Michael Feinberg, M.D., Ph.D., is Assistant Professor; Norman McI. James, M.D., Roger F. Haskett, M.D., and Meir Steiner, M.D., are Research Fellows; and Janet Tarika, M.A., is Research Associate, Clinical Studies Unit, Department of Psychiatry, University of Michigan. (Reprint requests to Dr. Carroll at Mental Health Research Institute, University of Michigan, Ann Arbor, Ml 48109.) 
discrimination between endogenous and nonendogenous (neurotic) depression has had strong predictive value for the DST response: Patients with nonendogenous depression have a very low frequency $(<4 \%$ ) of positive DST results (Carroll et al., $1976 b$, in press).

A recent study from Winokur's group in lowa described widely differing frequencies of positive DST results among genetic subtypes of patients with primary unipolar depression (Schlesser et al., 1979). The unipolar patients were classified according to the family history criteria of Winokur et al. (1978) into three subtypes: 1. Familial pure depressive disease-depression in a person who has a first-degree relative with a history of depression but not of mania, alcoholism, or antisocial personality. 2 . Sporadic depressive disease-depression in a person with no first-degree relative with alcoholism, antisocial personality, or depression. 3. Depression spectrum diseasedepression in a person who has a first-degree relative with alcoholism and/or antisocial personality, and who may or may not have a first-degree relative with depression. Abnormal DST results were found in $43 \%$ of the entire group. The frequencies were $82 \%$ in those with familial pure depressive disease; $37 \%$ in those with sporadic depressive disease; and only $4 \%$ in those with depression spectrum disease. Since these three subtypes could not be distinguished by clinical features, the clear implication of this report is that gentetic factors account for a major part of the heterogeneity observed in the DST results. The Winokur classification is not widely used in other centers, so no attempted replications of this study have yet appeared. In view of its potential importance, we have made a limited review of our own data to see whether we could support the study from Iowa.

\section{Methods}

Since our routine family history evaluations are less rigorous than those obtained by the lowa group, we could not be confident about assigning all our unipolar cases to their three subtypes. Therefore, we focused on a carefully documented group of patients with severe endogenous depression accompanied by affective delusions. The patients met the St. Louis criteria for primary unipolar depression (Feighner et al., 1972) and also the Research Diagnostic Criteria for primary unipolar major depressive disorder, endogenous and psychotic subtypes (Spitzer and Endicott, 1975). In each case the diagnosis was confirmed by our own clinical assessments (Feinberg et al., 1979). We had extensive contacts with family members in these cases (all inpatients), and we obtained family psychiatric histories from at least one relative in addition to the patients themselves.

Fourteen index cases with 28 ill relatives were identified, and the patients were classified according to the criteria of Winokur et al. (1978). All family history assessments were made by clinicians who were unaware of the DST results. For the critical diagnosis of alcoholism in the relatives, we had unequivocal descriptions of sustained abuse of alcohol, with functional impairment and adverse effects on family relationships. For sociopathy, only one first-degree relative met criteria. This person was described as having repeated arrests and trouble with the police, frequent charges of stealing goods, and an unstable occupational record. The diagnoses of depression in relatives were based on the descriptions given by the probands and at least one other 
relative. We accepted only descriptions of depressions that were episodic and required treatment, or that were terminated by suicide. We did not accept descriptions that referred to the relative as having a lifelong depressive personality, as being "frequently nervous," or as being admitted to the hospital "for nerves." Thus, our diagnoses of alcoholism and sociopathy in relatives would meet the family history research dianostic criteria used by Schlesser et al. (1979). Most of our diagnoses of depression in relatives also would meet these criteria. With respect to the categories of key interest for this study, errors in the diagnosis of depression among relatives would not alter the result. Such errors would lead to some patients' being reclassified only between the categories familial pure depressive disease and sporadic depressive disease. They would not lead to reclassification of relatives diagnosed as having depressive spectrum disease.

The DST was performed as described previously (Carroll et al., 1976a, 1976b). Blood samples were obtained for plasma cortisol determination at $0800 \mathrm{~h}, 1600 \mathrm{~h}$, and $2300 \mathrm{~h}$ after oral administration of dexamethasone $(1 \mathrm{mg}$ or $2 \mathrm{mg})$ at $2300 \mathrm{~h}$ the preceding night. By comparison, Schlesser et al. (1979) obtained only one blood sample at $0800 \mathrm{~h}$, and they used a $1 \mathrm{mg}$ dose of dexamethasone.

In selecting this particular group of patients for study, we had one further methodological issue in mind: The frequency of abnormal DST results is especially high among psychotic (delusional) endogenous depressive patients (Carroll et al., 1976b). Thus, this population would present a very stringent test of the Iowa report, so that a confirmation of their findings in these patients would be strong support indeed.

\section{Results}

There were two cases subtyped as familial pure depressive disease, five as sporadic depressive disease, and six as depression spectrum disease. One patient (\#14) could not be classified since she had a daughter with bipolar manic-depressive illness (Table 1). Seven patients were male, and seven female, the median age at the time of study being 60 years. Nine patients were experiencing at least the third episode of depression, two were in their second episode, and three were seen in their first episode. The mean ages of onset of episodes were: familial pure depressive disease, 47 years; sporadic depressive disease, 43 years; depression spectrum disease, 45 years.

The family psychiatric histories obtained in these 14 patients are listed in Table 2 , where both the first- and second-degree ill relatives are recorded. Two of the patients classified as sporadic depressive disease had definite second-degree family histories of alcoholism. A strong first-degree history of alcoholism was found in the unclassified patient (\#14). By definition, all patients with depression spectrum disease had a first-degree history of alcoholism or sociopathy, and half of them also had a firstdegree history of depression.

The results of the DSTs among these patients with primary psychotic endogenous unipolar depression are shown in Table 3. Overall, 11 of the 14 patients (79\%) had a positive test result. The frequency of positive tests was $50 \%$ in familial pure depressive disease, $80 \%$ in sporadic depressive disease, and $83 \%$ in depression spectrum disease. For this analysis we have used the plasma cortisol criterion level of $5 \mu \mathrm{g} / \mathrm{dl}$, in keeping with Schlesser et al. (1979). When the analysis is restricted to the $0800 \mathrm{~h}$ plasma cortisol 
level (which was the only sample obtained by Schlesser et al.), then the frequency of abnormal results in the three genetic subtypes is: familial pure depressive disease, $0 \%$; sporadic depressive disease, $60 \%$; and depression spectrum disease, $60 \%$ (one missing case at $0800 \mathrm{~h}$ ).

Table 1. Characteristerics of 14 patients with primary psychotic endogenous unipolar depression

\begin{tabular}{cccccc}
\hline Patient & Age & Sex & $\begin{array}{c}\text { Previous } \\
\text { episodes }\end{array}$ & $\begin{array}{c}\text { Age } \\
\text { at onset }\end{array}$ & $\begin{array}{c}\text { Winokur } \\
\text { subtype }\end{array}$ \\
\hline 1 & 68 & M & 4 & 62 & FPDD \\
2 & 51 & M & 4 & 31 & FPDD \\
3 & 52 & F & 3 & 42 & SDD \\
4 & 67 & F & 0 & 67 & SDD \\
5 & 28 & F & 0 & 28 & SDD \\
6 & 68 & M & 9 & 46 & SDD \\
1 & 31 & F & 0 & 30 & SDD \\
8 & 73 & F & 4 & 57 & DSD \\
9 & 66 & F & 1 & 54 & DSD \\
10 & 53 & M & 2 & 43 & DSD \\
11 & 62 & M & 4 & 47 & DSD \\
12 & 83 & M & 4 & 47 & DSD \\
13 & 67 & M & 1 & 24 & DSD \\
14 & 73 & F & 3 & 24 & - \\
\hline
\end{tabular}

FPDD: familial pure depressive disease.

SDD: sporadic depressive disease.

DSD: depression spectrum disease.

\section{Discussion}

In this study the DST did not discriminate among the three familial subtypes of unipolar depressives. In particular, the patients with depression spectrum disease had a high frequency of abnormal test results. By the procedure of Schlesser et al. (1979), the frequency in this group was $60 \%$, while with our own extended test procedure (Carroll et al., 1976a; 1976b) it was $83 \%$. Both these results are distinctly greater than the $4 \%$ frequency reported by Schlesser et al. (1979). 


\begin{tabular}{|c|c|c|}
\hline $\begin{array}{l}\text { Winokur } \\
\text { subtype }\end{array}$ & Patient & Family history \\
\hline FPDD & 1 & $\mathrm{M}, \mathrm{N}$ depression and suicide \\
\hline FPDD & 2 & $\begin{array}{l}\mathrm{F} \text { depression and suicide } \\
\mathrm{S} \text { depression }\end{array}$ \\
\hline SDD & 3 & Nil \\
\hline SDD & 4 & Nil \\
\hline SDD & 5 & PU, PU, PU alcoholic \\
\hline SDD & 6 & MGM alcoholic \\
\hline SDD & 7 & MA depression, ECT \\
\hline DSD & 8 & $\begin{array}{l}\text { B alcoholic } \\
B, S, S \text {, son depression }\end{array}$ \\
\hline DSD & 9 & S alcoholic \\
\hline DSD & 10 & $\begin{array}{l}\text { D sociopathic } \\
\text { B depression }\end{array}$ \\
\hline DSD & 11 & B alcoholic \\
\hline DSD & 12 & F alcoholic \\
\hline DSD & 13 & $\begin{array}{l}\text { B alcoholic } \\
\text { B,B,S depression }\end{array}$ \\
\hline - & 14 & $\begin{array}{l}\mathrm{F}, \mathrm{B} \text {, son alcoholic } \\
\text { B depression } \\
\mathrm{D} \text { bipolar I manic-depressive }\end{array}$ \\
\hline
\end{tabular}

B: brother; D: daughter; F: father; M: mother; N: niece; S: sister; MA: maternal aunt; MGM: maternal grandmother; PU: paternal uncie; ECT: electroconvulsive therapy.

The highly selected nature of our population (and its small size) must be kept in mind when our results are compared with those of the Iowa group. As noted earlier, a confirmation of their results with our psychotic depressive patients would have been very significant. The findings we report here, however, do not necessarily disprove the work of Schlesser et al. (1979). Only a larger study of more typical patients would constitute a definitive attempt to replicate their work. I hus, the major conclusions we wish to draw from our present results are (1) abnormal DST responses certainly do occur in delusional patients with depression spectrum disease, and (2) the heterogeneity of DST results among patients with endogenous depression cannot be accounted for by genetic factors alone.

If the severity of illness in the patients reported here is considered, it may be possible to reconcile our results with those of Schlesser et al. (1979) by means of a threshold model for HPA activation. This model would propose that patients with depression spectrum disease have a higher threshold than the other subtypes do, so that abnormal DST results would not be found unless patients with very severe illness (such as our delusional cases) were examined. 
Table 3. Results of overnight dexamethasone suppression tests in 14 patients with primary psychotic endogenous unipolar depression.

\begin{tabular}{|c|c|c|c|c|c|c|}
\hline $\begin{array}{l}\text { Winokur } \\
\text { subtype }\end{array}$ & Patient & $\begin{array}{l}\text { Dexamethasone } \\
\text { dose (mg) }\end{array}$ & \multicolumn{3}{|c|}{$\begin{array}{c}\text { Postdexamethasone } \\
\text { plasma cortisol }(\mu \mathrm{g} / \mathrm{dl})\end{array}$} & $\begin{array}{l}\text { Abnormal } \\
\text { test result }\end{array}$ \\
\hline FPDD & 1 & 2 & 0.6 & 7.6 & 6.2 & + \\
\hline FPDD & 2 & 1 & 2.1 & 0.6 & 0.9 & - \\
\hline SDD & 3 & 1 & 1.7 & 17.8 & 11.0 & + \\
\hline SDD & 4 & 1 & 11.3 & 4.7 & 5.6 & + \\
\hline SDD & 5 & 1 & 5.3 & 4.1 & 3.3 & + \\
\hline SDD & 6 & 1 & 26.3 & 22.5 & 11.6 & + \\
\hline SDD & 7 & 2 & 0.7 & 1.2 & 0.6 & - \\
\hline DSD & 8 & 1 & 0.7 & 1.2 & 4.1 & - \\
\hline DSD & 9 & 1 & 6.0 & 4.1 & 4.4 & + \\
\hline DSD & 10 & 1 & 14.1 & 9.2 & - & + \\
\hline DSD & 11 & 2 & - & 4.2 & 15.9 & 1 \\
\hline DSD & 12 & 2 & 2.1 & 15.0 & 8.7 & + \\
\hline DSD & 13 & 1 & 8.3 & 15.5 & 14.5 & + \\
\hline- & 14 & 1 & 15.0 & 18.0 & 17.7 & + \\
\hline
\end{tabular}

All plasma cortisol levels should be $<5 \mu \mathrm{g} / \mathrm{dl}$ for a normal result.

If this threshold model is correct, however, it would tend to go against the lowa proposal that the three subtypes are "separate illnesses." Since these three variants of unipolar depressive illness are not distinguishable clinically (Van Valkenburg et al., 1977; Schlesser et al., 1979), they may indeed be the same affective disorder, but with genetically determined differences in their threshold for neuroendocrine activation. In fact, except for the DST finding of Schlesser et al. (1979), the Winokur classification has only weak support from two features, namely, age at onset and number of episodes (Winokur et al., 1978). Both of these could also be regarded as threshold functions.

A threshold model of HPA activation could be useful also for understanding the very high frequency of abnormal DST results (almost double the usual rate) observed in all the delusional depressives. This finding is not related simply to the presence of psychosis, since other kinds of psychotic patients (schizophrenics) consistently have normal DST responses (Carroll et al., 1976b; Brown et al., 1979; Schlesser et al., 1979). Thus, the high frequency of neuroendocrine disturbance in psychotic depressives may be determined by the extreme severity of depressive symptoms and by the specific affective quality of their delusions.

In this respect it can be noted that delusional depressives, more than any other subgroup of patients with endogenous depression, manifest the "distinct quality" of dysphoric mood emphasized by many nosologists (e.g., Mendels and Cochrane, 1968). This feature was recognized by early clinicians (Kraepelin, 1904, 1921; Gillespie, 1926) and was described as a uniquely aversive, anguished, or uncomfortable experience: "painful tension," "torment" (Kraepelin, 1921); something "formless . . vague and very unpleasant in tone. From this arose the difficulty that these patients so frequently had in expressing their condition to the physician" (Gillespie, 1926). Because this 
concept has been difficult to define operationally, it is now usually described as what it is not, rather than as what it actually is (see the Research Diagnostic Criteria, for example). We regard it as a severe form of the disinhibition of central pain mechanisms discussed by Donald Klein (Klein and Davis, 1969; Klein, 1974).

Since pain itself can cause disinhibited HPA activity (Allen et al., 1973), this distinctive, though poorly understood "psychic pain" of endogenous depressives may be a critical determinant of the abnormal DST responses. The heterogeneity of DST responses could then be related to variations firstly in the severity of this clinical feature among patients, and secondly in their thresholds for neuroendocrine activation by pain mechanisms.

These two sources of variance, combined with the lack of operational means to characterize the experience of "psychic pain," may well account for the fact that a distinctive clinical profile of endogenous depressive patients with abnormal DST responses has not yet emerged. The formulation proposed above would be consistent also with our findings of a high frequency of abnormal DST responses in two other conditions, namely, mixed manic-depressive states and depressed-type schizoaffective disorder (Carroll et al., unpublished observations). In both cases a severe dysphoria of the distinctive endogenous type is observed. Experimental studies of the HPA response to pain among endogenous depressive patients, including the Winokur subtypes, are suggested to test these possible sources of variance in DST responses.

\section{References}

Allen, J.P., Allen, C.F., Greer, M.A., and Jacobs, J.J. Stress-induced secretion of ACTH. In: Brodish, A., and Redgate, E.S., eds. Brain-Pituitary Adrenal Interrelationships. Karger, Basel (1973).

Brown, W.A., Johnston, R., and Mayfield, D. The 24-hour dexamethasone suppression test in a clinical setting: Relationship to diagnosis, symptoms and response to treatment. American Journal of Psychiatry, 136, 543 (1979).

Carroll, B.J. The hypothalamic-pituitary-adrenal axis in depression. In: Davies, B., Carroll, B.J., and Mowbray, R.M., eds. Depressive Illness: Some Research Studies. Charles C Ihomas, Springfield, IL (1972).

Carroll, B.J. The hypothalamus-pituitary-adrenal axis in depression. In: Burrows, G., ed. Handbook on Depression. Elsevier/North-Holland, Amsterdam (1977).

Carroll, B.J. Ncuroendocrine function in psychiatric disorders. In: Lipton, M.A., DiMascio, A., and Killam, K.F., eds. Pslchopharmacology: A Generation of Progress. Raven Press, New York (1978).

Carroll, B.J., Curtis, G.C., and Mendels, J. Neuroendocrine regulation in depression. I. Limbic system-adrenocortical dysfunction. Archives of General Psychiatry, 33, 1039 (1976a).

Carroll, B.J., Curtis, G.C., and Mendels, J. Neuroendocrine regulation in depression. II. Discrimination of depressed from non-depressed patients. Archives of General Psychiatr.', 33, 1051 (1976b).

Carroll, B.J., and Davies, B.M. Clinical associations of 11-hydroxycorticosteroid suppression and non-suppression in severe depressive illness. British Medical Journal, 1, 789 (1970).

Carroll, B.J., Feinberg, M., Steiner, M., Ilaskett, R.F., James, N. McI., and Tarika, J. Diagnostic application of the dexamethasone suppression test in depressed outpatients. In: Mendlewicz, J., ed. Advances in Biological Psychiatry. Elsevier/North-Holland, Amsterdam (in press).

Carroll, B.J., and Mendels, J. Neuroendocrine regulation in affective disorders. In: Sachar, E. J., ed. Hormones, Behavior and Psvchopathology. Raven Press, New York (1976). 
Feighner, J.P., Robins, E., Guze, S.B., Woodruff, R.A., Winokur, G., and Munoz, R. Diagnostic criteria for use in psychiatric research. Archives of General Psychiatry, 26, 57 (1972).

Feinberg, M., Carroll, B.J., Steiner, M., and Commorato, A. Misdiagnosis of endogenous depression with the Research Diagnostic Criteria. Lancet, I, 267 (1979).

Gillespie, R.D. Discussion on manic-depressive psychosis. British Medical Journal, II, 878 (1926).

Klein, D.F. Endogenomorphic depression: A conceptual and terminological revision. Archives of General Psychiatry, 31, 447 (1974).

Klein, D.F., and Davis, J.M. Diagnosis and Drug Treatment of Psychiatric Disorders. The Williams \& Wilkins Company, Baltimore (1969).

Kraepelin, E. Lectures on Clinical Psychiatry. Bailliere, Tindal and Cox, London (1904).

Kraepelin, E. Manic Depressive Insanity and Paranoia. Translated by M. Barclay. Livingstone, Edinburgh (1921).

Mendels, J., and Cochrane, C. The nosology of depression: The endogenous-reactive concept. American Journal of Psychiatry, 124 (Suppl.), 1 (1968).

Schlesser, M.A., Winokur, G., and Sherman, B.M. Genetic subtypes of unipolar primary depressive illness distinguished by hypothalamic-pituitary-adrenal axis activity. Lancet, I, 739 (1979).

Spitzer, R.L., and Endicott, J. Research Diagnostic Criteria. 2nd ed. New York State Psychiatric Institute, New York (1975).

Van Valkenburg, C., Lowry, M., Winokur, G., and Cadoret, R. Depression spectrum disease versus pure depressive disease. Journal of Nervous and Mental Disease, 165, 341 (1977).

Winokur, G., Behar, D., Van Valkenburg, C., and Lowry, M. Is a familial definition of depression both feasible and valid? Journal of Nervous and Mental Disease, 166, 764 (1978). 